Advances in Computational Sciences and Technology

ISSN 0973-6107 Volume 11, Number 1 (2018) pp. 69-76

(C) Research India Publications

https://dx.doi.org/10.37622/ACST/11.1.2018.69-76

\title{
Adoption Models for Agile Software Development Projects
}

\author{
Raju D. Dhole \\ Research Scholar, M.S. Ramaiah University of Applied Sciences, Bangalore, \\ Karnataka, India. \\ (Designated Corresponding author)
}

\author{
Dr. K.M. Sharath Kumar
}

Deputy Director - Sponsored Research, M. S. Ramaiah University of Applied Sciences, Bangalore, Karnataka, India.

\begin{abstract}
Software development projects have undergone significant changes from early 2000s. As per the study conducted by Gartner Inc., spending on Information Technology (IT) projects in the year 2017 will reach USD 3.5 trillion approximately. Agile methods used in software development projects work on an iterative and incremental development process, where requirements and solutions evolve through continuous collaboration between customer and business organization through cross-functional teams.

Every year VersionOne ${ }^{\circledR}$ conducts a survey for adoption and usage of agile methodologies in IT industry. As per results from the survey, most organizations are either using agile methods for managing their software development projects or planning to use them in near future. This study emphasizes on the critical review of adoption models in management of software development projects using agile methods from the literature and best practices from Information Technology (IT) industry. Results show that adoption models of agile methods lack unified approach to consider all the characteristics (Adequacy, Capability and Effectiveness) along with its risks for managing the projects on software development. Research directions also portray that adoption models for managing the software development projects in industry should use agile methods in future. Further, there is a need and scope to conduct research in the form of a model or framework development which can interlink characteristics
\end{abstract}


like Adequacy, Capability and Effectiveness along with its risks to arrive at success parameters. An empirical study with respect to Indian IT industry to arrive at the success parameters may also be looked as the way forward.

Keywords: Maturity Models, Risk Models, Success Parameters, Project Outcome

\section{INTRODUCTION:}

Project is a temporary endeavor undertaken to create a unique product, service or result. "Project Management" is the application of knowledge, skills, techniques and tools to manage the activities for meeting the customer requirements (Project Management Institute). Prior to 2000, various methods like Waterfall, Spiral and Rapid Application Development (RAD) were used for software development projects (Raval and Rathod, 2013). In particular, these methods were also deemed as "Traditional" methods of managing the projects on software development. On the other hand, the software development projects were managed with the focus on cost and schedule during 1990s. This approach underwent a change from early 2000s wherein the focus of software development projects shifted from managing cost and schedule to achieving the business functionality or benefits delivered to the end user. This approach warranted for the development of agile methods for managing the life cycle of software development projects (Padalkar and Gopinath, 2016). An agile manifesto was released in the year 2001 by a group of seventeen independent minded software practitioners (Agile manifesto, 2001). Further, studies have highlighted the impact of agile methods in the overall success of software development projects compared to traditional methods (Dikert et al., 2016). Every year VersionOne ${ }^{\circledR}$ conducts survey with participants from a broad range of industries in the global software development community to provide inputs about their adoption and usage of agile methodologies. Results from the survey show that there is a positive trend towards adopting the agile methods for managing the software development projects (VersionOne, 2016).

In this study, research papers focusing on adoption of agile methods were critically reviewed. In parallel, IT industry adoption practices (Smillie, 2014; Alhawari, 2012; Sidky, 2007) for traditional and agile method were analyzed. Findings warrant for critique and comparison of the adoption models from the literature and the industry that are used to manage software development projects. Therefore, this study aims to address this issue in the form of the review paper.

This study outlines the focus on characteristics like Adequacy, Capability and Effectiveness along with assessment of risks for the management of software development projects. Further, an attempt to critique and compare agile adoption models from the literature and the IT industry was carried out. Characteristics addressed by each model for agile adoption from the literature was highlighted. It was observed that the literature has good coverage of models for agile adoption. However, these models focus on some of the characteristics like Adequacy, Capability, Effectiveness and its risk. Findings also indicate that focus on 'traditional methods' for managing 
software development projects used in IT industry is becoming outdated. On the other hand, IT industry is looking towards agile methods through maturity assessment model for managing the software development projects. Hence, there is a need to review and compare adoption models in management of software development projects using agile methods in literature and IT industry.

\section{Usage of Agile Methods and Outcomes:}

Usage of traditional and agile methods for managing the software development projects were studied and reported as shown in Figure 1 (Vijayasarathy, 2016). Results indicate that agile methods have found higher adoption percentage compared to traditional or iterative methods.

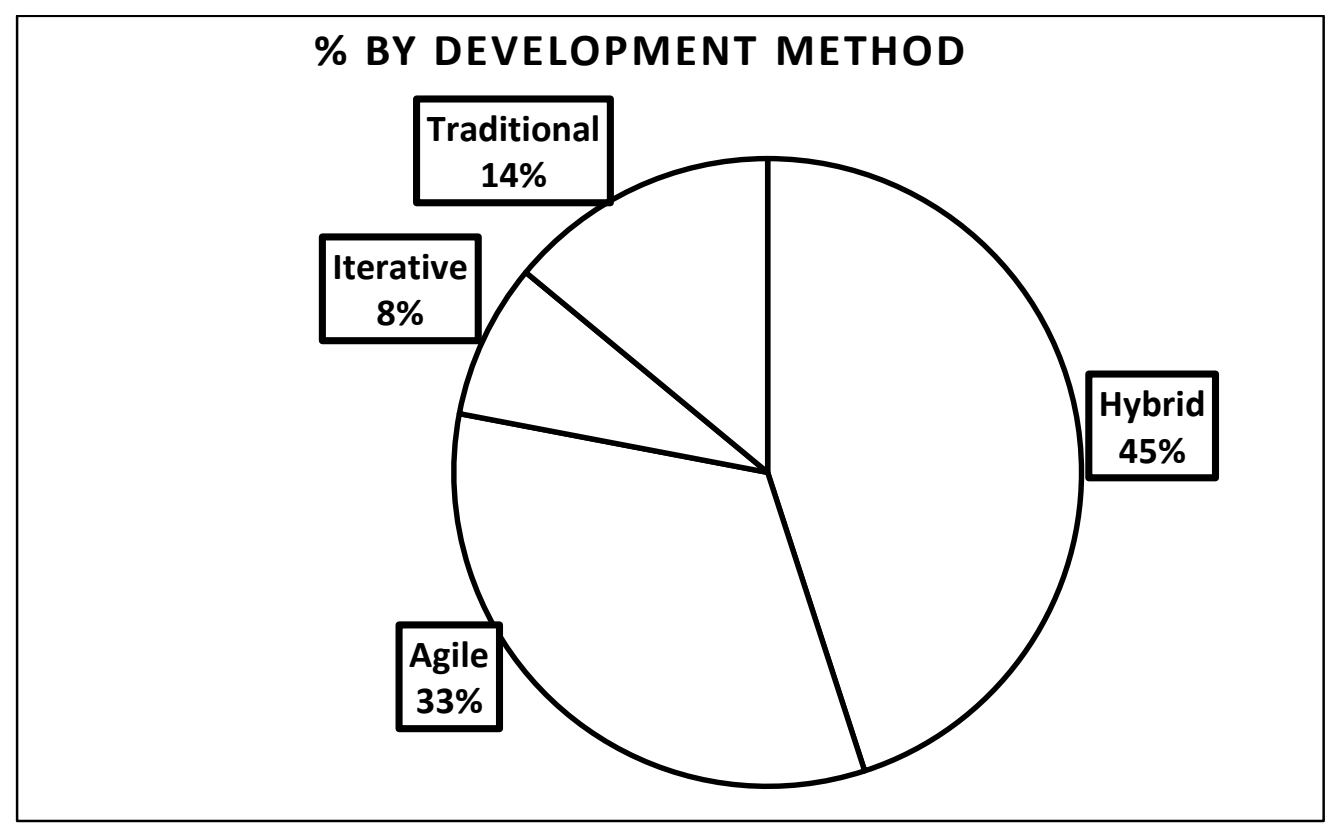

Figure 1 - Percentage of Software Development Method Usage

Every year VersionOne ${ }^{\circledR}$ conducts survey with participants from a broad range of industries in the global software development community to provide inputs about their adoption and usage of agile methodologies. Participants to the survey include members from top, middle and lower management level across IT companies of all sizes. The survey also highlights the value delivered by agile development software projects (VersionOne, 2016). Hence, there is a positive trend towards adopting the agile methods for managing the software development projects. This trend is further substantiated by the survey results conducted by VersionOne ${ }^{\circledR}$ as depicted in Figure 2. 


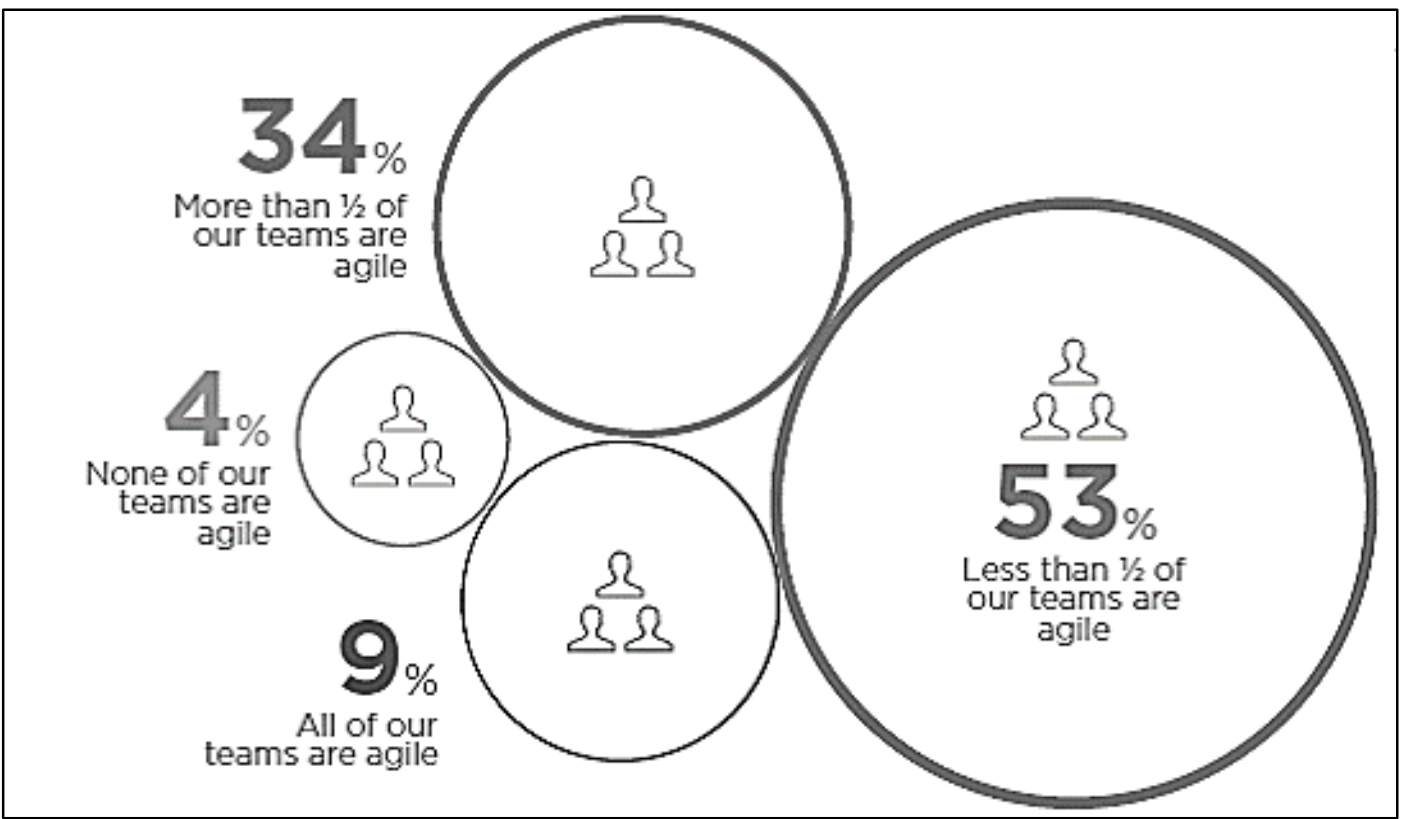

Figure 2 - Percentage of Teams in an Organization Using Agile

Results reveal that $43 \%$ of the organizations use agile methods for managing the software development projects. (VersionOne, 2016)

\section{Comparison of Adoption Models for Agile Methods from Literature:}

In this study, an attempt to critique and compare the Adoption Models for Agile Methods from Literature was carried out. Following models for agile software development were reviewed and compared:

1. Objectives, Principles and Practices (OPP) Model: This model assess "Goodness" of agile methods using characteristics like Adequacy, Organization Capability and Effectiveness, (Soundararajan and Arthur, 2011)

2. Value Model: Perception of "value" among software development organizations will be captured. In particular, on-time delivery of software projects is identified as the most important value (Alahyari, 2017)

3. Risk Model: This model focuses on distributed agile development. Specifically, risk categories with high impact like Group Awareness and External Stakeholder Collaboration will be included (Shrivastava and Rathod, 2017)

4. Hybrid Model: This model includes the impact of contextual factors on software development approaches that are hybrid in nature. Moreover, 'Hybrid' approaches are the result of natural evolution of process driven by learning and experience (Kuhrmann, 2017).

After analyzing the various adoption models of agile methods, Table 3 shows the comparison of models using various characteristics: 
Table 3. Comparison of Agile Models

\begin{tabular}{|c|c|c|c|c|}
\hline Characteristics & OPP Model & Value Model & Risk Model & Hybrid Model \\
\hline Adequacy & $\mathrm{X}$ & $\mathrm{X}$ & $\mathrm{X}$ & $\mathrm{X}$ \\
\hline Capability & $\mathrm{X}$ & $\mathrm{X}$ & $\mathrm{X}$ & $\mathrm{X}$ \\
\hline Effectiveness & $\mathrm{X}$ & $\mathrm{X}$ & $\mathrm{X}$ & \\
\hline Challenges/Risks & & & $\mathrm{X}$ & $\mathrm{X}$ \\
\hline Success Factors & $\mathrm{X}$ & $\mathrm{X}$ & & $\mathrm{X}$ \\
\hline Outcome Correlation & $\mathrm{X}$ & $\mathrm{X}$ & $\mathrm{X}$ & \\
\hline
\end{tabular}

The comparison of models from the literature as outlined in Table 3 shows that OPP model and Value model has good coverage of characteristics except risks. Nonetheless, Risk model covers all the characteristics except success factors. On the other hand, Hybrid model has the least coverage of characteristics.

\section{Comparison of Traditional and Agile Models from Industry:}

IT industry uses various models to evaluate the characteristics responsible for positive outcome of the software development project. Following are the critical models used in the IT industry:

1. Seven Keys to Success: This model uses 7 keys covering stakeholders, business benefits, work/schedule, team, scope, risks and organization benefits for assessing the health of the project using Red, Yellow and Green status indicators (Smillie, 2014)

2. Risk Management Model: The model involves identification, analysis, response planning and execution for risks. Moreover, mitigation of risk is planned based on perceived severity and impact of the risk (Alhawari, 2012)

3. Agile Maturity Assessment Model: This framework provides guidance on how to adopt agile framework. It identifies the right agile practices for an organization moving to agility. This framework evaluates the practices implemented in the project against the standard practices defined by agile methods. In addition, the Maturity Assessment Model introduces structure in a complex and unpredictable process like agile adoption. It also measures responsiveness of the adoption models independent of agile method (Sidky, 2007). 
Table 4 shows the comparison of IT Industry models for software development projects:

Table 4. Comparison of IT Industry Models

\begin{tabular}{|c|c|c|c|}
\hline Characteristics & Risk Model & 7 Keys Model & $\begin{array}{c}\text { Agile Maturity } \\
\text { Assessment Model }\end{array}$ \\
\hline Model Usage & Traditional & Traditional & Agile \\
\hline Adequacy & $\mathrm{X}$ & $\mathrm{X}$ & $\mathrm{X}$ \\
\hline Capability & $\mathrm{X}$ & $\mathrm{X}$ & $\mathrm{X}$ \\
\hline Effectiveness & & $\mathrm{X}$ & $\mathrm{X}$ \\
\hline Challenges/Risks & $\mathrm{X}$ & $\mathrm{X}$ & $\mathrm{X}$ \\
\hline Process Maturity & & $\mathrm{X}$ & $\mathrm{X}$ \\
\hline Success Factors & $\mathrm{X}$ & & \\
\hline Outcome Correlation & $\mathrm{X}$ & $\mathrm{X}$ & \\
\hline
\end{tabular}

Comparison of model from IT industry as outlined in Table 4 shows that the traditional models are still prevalent in the IT industry. It was identified that the risk model do not take into consideration the effectiveness and process maturity. Similarly, 7 Keys model lack in coverage of success factors. It was suggested that the appropriate adoption model for agile methods is usage of assessment maturity matrix. The agile maturity assessment provides the process compliance rather than focusing on effectiveness of the methods. Based on these findings, identifying the appropriate adoption model for agile methods can be one of the line of sight for further research.

\section{Inference from Critical Review and Comparison of Literature and IT Industry Best Practices:}

Comparison of agile models from the literature shows that most of the research were focused on linking of characteristics like Adequacy, Organization Capability and Effectiveness to risks, values and challenges to arrive at success parameters. Therefore, focus on linking success parameters to agile project outcome parameters can be one of the research directions. For instance, studies by Soundararajan and Arthur (2011) for 'Goodness' of agile methods favors usage of OPP model. Similarly, research from Alahyari (2017) opts for 'Value' model and Shrivastava and Rathod (2017) warrants for risk model.

IT industry usage of various adoption models for agile methods were studied with respect to usage in software development projects. The findings show that IT industry practices mostly focus on traditional methods till date. In particular, Seven Keys model (Smillie, 2014), Risk model (Alhawari, 2012) do not have specific focus on agile methods. On the other hand, maturity assessment (Sidky, 2007) model is deemed appropriate for the implementation of agile methods. However, there is an enormous potential for using agile methods in managing the software development projects. 


\section{CONCLUSION:}

A comparison of adoption models used for the implementation of agile methods for managing the software development projects from the literature and the IT industry is presented. Findings from the review of agile methods can be used to further assess the impact of characteristics like Adequacy, Capability, Effectiveness and assessment of its risks on the success of software development projects. Furthermore, these characteristics could be used as success parameters for the future research directions. An attempt to establish the relationship between the success parameters and project outcome may also be the subject of empirical study. Further, findings from the empirical study may be used to create a model in order to link success parameters with the software development project outcome.

Other areas that could be considered for further study are linking of project risks to outcome and development of definitive guidelines for the transition from "traditional" to "agile" methods for managing the software development projects.

\section{LIMITATIONS OF STUDY AND RESEARCH DIRECTIONS:}

The study focused on usage of agile methods for managing software development projects from literature and industry best practices. This study covered the available literature from the key project management journals from 2010 to 2017 focusing on specific models used for managing agile projects. Hence, there is a possibility to look at the research progress before 2010 as well. The study focused on specific characteristics like Adequacy, Capability, Effectiveness and Risks warranting to identify new characteristics based on the line of sight of the research directions. The study also highlights the specific methods in IT industry that are used primarily for traditional methods and lack mathematical models/frameworks specifically addressing agile methods for managing software development projects.

\section{REFERENCES:}

[1] What is a project and what is project management, PMI, Retrieved from, https://www.pmi.org/about/learn-about-pmi/what-is-project-management

[2] Raval R, Rathod H M (2013), Comparative Study of Various Process Model in Software Development, International Journal of Computer Applications, 82(18) pp. 16-19.

[3] Padalkar M, Gopinath S (2016), Six decades of project management research: Thematic trends and future opportunities, International Journal of Project Management 34 (2016), pp. 1305-1321.

[4] Agile manifesto - $2001 . \quad$ Retrieved from http://agilemanifesto.org/principles.html

[5] Dikert K, Paasivaara M, Lassenius C (2016), Challenges and success factors for large-scale agile transformations: A systematic literature review, Journal of 
systems and software, Vol 119 pp. 87- 108

[6] VersionOne state of agile survey, (2016). Retrieved from https://explore.versionone.com/state-of-agile.

[7] Smillie B (2014), Seven Keys to Success, Retrieved from http://www.uruq.com/download/7420.html

[8] Alhawari S, Karadsheh L, Nehari-Talet A, Mansour E (2012), Knowledge Based Risk management for information technology projects, International Journal of information management, Issue 32, pp. 50-65

[9] Sidky A, A Structured Approach to Adopting Agile Practices: The Agile Adoption Framework (2007), PhD Thesis submitted to Virginia Polytechnic Institute and State University, Blacksburg, Virginia.

[10] Vijayasarathy L R, Butler C W, (2016) Choice of Software Development Methodologies, Do Project, Team and Organizational Characteristics Matter? IEEE software, 33(5), pp. 1-12.

[11] Soundararajan S and Arthur J D (2011), A Structured Framework for Assessing the "Goodness" of Agile Methods, 18th IEEE International Conference and Workshops on Engineering of Computer-Based Systems, June 2011, pp 14-23.

[12] Alahyari H, Svensson R B, Gorschek T (2017), A Study of Value in Agile Software Development Organizations, The Journal of Systems \& Software, Volume 125, pp. 171- 288

[13] Shrivastava S V, Rathod U (2017), A Risk Management Framework for Distributed Agile Projects, Information and Software Technology, Volume 85, pp. 1-15.

[14] Kuhrmann M, Tell JPM, Garousi V, Felderer M, Trektere K, McCaery F, Linssen O, Hanser E, Prause CR (2017), Hybrid Software and System Development in Practice: Waterfall, Scrum, and Beyond, Proceedings of International Conference on Software System Process, July 5 to 7, Paris France, pp. 1-10.

[15] Gartner press release (2016) Gartner Says Global IT Spending to reach $\$ 3.5$ Trillion in 2017, Retrieved from http://www.gartner.com/newsroom /id/3482917 (Accessed 14 Sep 2017) 